of the Department of Health and Human Services. The agency will initially get $\$ 1$ billion over two years to fund civilian research on countermeasures to bioterror and pandemic threats.

Senator Richard Burr (Republican, North Carolina), who sponsored the bill, describes BARDA as "an aggressive venture capitalist" that will partner universities and companies to help them through middle- and late-stage drug development and manufacture. The bill had broad bipartisan support, including co-sponsorship by Senator Edward Kennedy (Democrat, Massachusetts), whose state is a hub of biotechnology firms, and Senator Hillary Clinton (Democrat, New York), whose constituents suffered the most in the attacks of 11 September 2001.

The BARDA bill has long been a darling of industry, which had lobbied for its passage. Its backers noted that the \$5.6-billion Project BioShield, which was passed into law in 2004, provides funds for the government to buy vaccines and drugs once they are ready for use. At earlier stages in drug and vaccine development - stages the industryhas termed the "Valley of Death' - companies are therefore left to push forward at their own expense.

"This legislation recognizes that the "Valley of Death' remains a barrier to effective countermeasure product development," Jim Greenwood, a former Republican congressman who is president of the Washington-based Biotechnology Industry Organization, said in a statement after the Senate passed the measure to create BARDA.

Other proponents argue that developing agents to tackle what are only potential attacks and pandemics is far riskier than investing in a new diabetes medicine, for example, and that it's reasonable to expect the government to share that risk. "It's like a B2 bomber," says Francesca Cook, vice-president of policy and government affairs at PharmAthene, a company based in Annapolis, Maryland, that is developing prophylactics and treatments against anthrax and chemical nerve agents. "Only the Department of Defense is going to buy that."

But critics say the bill is a blatant giveaway to business, a security risk and a wasteful move in an era of ballooning federal deficits.

"I don't know when this terrible cycle of splurging on biodefence is going to end," says Ed Hammond, director of the US office of the Sunshine Project, a bioweapons watchdog group based in Austin, Texas, and Hamburg, Germany. "I don't think we need nearly 20,000 people at over 400 institutions researching biological weapons agents.

Hammond refers to numbers compiled by the US Centers for Disease Control and Prevention in Atlanta, Georgia, which reports periodically on the number of people and institutions registered to handle potential bioweapons agents. He worries that the sheer number of people involved in such research increases US vulnerability to domestic terrorism, and encourages other countries to enter a race that could lead to the offensive use of biological weapons.

Fiscal conservatives also bemoaned the BARDA bill's passage by a Congress that has spent $\$ 26.7$ billion on civilian biodefence since 2001 . 'The creation of a new office is always suspect," says Tom Finnigan, a spokesman for Citizens Against Government Waste, a Washington-based group that monitors government spending, "because it will be duplicating roles that already exist. And it will never go away. Even if they stockpile all the vaccines they need, the office won't dose down. It will expand its mission, inevitably."

The other bill passed in the small hours on Saturday was the National Institutes of Health Reform Act of 2006. For the first time since 1993, it offers broad guidance and new requirements for the structure and running of the NIH. Barton, the bill's author, noted that even as the agency's budget doubled between 1998 and 2003 , its "hodge-podge" structure was left untouched.

The bill caps the number of institutes at the current 27 , and requires the agency's director to submit biennial reports to Congress cataloguing all NIH research and justifying the individual institutes' priorities. It requires the $\mathrm{NIH}$ to set up a user-friendlyelectronic system to uniformly code all its grants and activities. And it establishes a 'common fund', comprising up to $5 \%$ of the total NIH budget in any given year, for research involving more than one $\mathrm{NIH}$ institute. But the most eye-catching provision is a funding boost that would increase the biomedical agency's budget by more than $\$ 4$ billion to $\$ 32.8$ billion in 2008 .

But there is no guarantee that the money will materialize. That remains in the hands of the congressional appropriating committees that

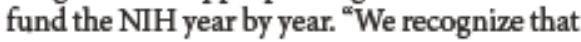
it's not money in the bank and that we'll have to convince appropriators to do the same," says Howard Garrison, a spokesman for the Federation of American Societies for Experimental Biology. "But this is a good sign. It's a strong endorsement of the NIH."

Meredith Wadman
ZOO

NEWS

Locals in the

English town of

Borwick, Lancashire,

were baffled when

a seal turned up in a

grassy roadside verge

- more than 6 kilometres

inland and some 1.5 kilometres

from the nearest river. Despite

its apparently heroic overland

journey, the disorientated

trekker, now nicknamed Sid, bore

not a scratch.

\section{ON THE RECORD}

\section{'Maybe we'll find out that spaceflight turned out to be a historical aberration, like Zeppelins."}

John Pike, director of scientific monitoring group GlobalSecurity.org. on whether projects such as the International Space Station might lose impetus.

\section{"Given... the risks of a pandemic originating from the Hajj, mandatory influenza vaccination for all pilgrims should be considered."}

An editorial in the $B M J$ ponders the flu risks of the annual gathering of some 2 million Muslims in Mecca.

\section{NUMBER CRUNCH}

$\mathbf{2 5} \%$ is the cut incodquotas to be imposed for 2007 by the European Commission after commissioners said that independent experts did not provide "clear quantitative scientificadvice".

$\mathbf{O}$ is the unequivocal amount of cod the International Council for Exploration of the Sea (ICES) advises should be taken from European waters in 2007 to best preservestocks.

5 is the number of years that the ICES has been advising that the quantity of cod caught in European waters should be zero, without being heeded by the European Commission.

Sources: The Guardian, BML, Emvironment News Service 